\title{
RELACIONAMENTO COMERCIAL EM CANAIS DE DISTRIBUIÇÃO: ANALISE SEGUNDO OS PEQUENOS SUPERMERCADOS DE BAIRRO ${ }^{1}$
}

\section{COMMERCIAL RELATIONSHIP IN DISTRIBUTION CHANNEL: ANALYSIS ACCORDING TO THE NEIGHBORHOODS SMALL SUPERMARKETS}

\author{
Gessuir Pigatto ${ }^{2}$ \\ Giuliana Aparecida Santini ${ }^{3}$ \\ Janaina Ferreira de Souza ${ }^{4} 5$
}

RESUMO: O mercado varejista passa por mudanças demandadas por alterações do comportamento do consumidor, que busca cada vez mais conveniência, alterações do ambiente econômico com a estabilização econômica e mudanças na estrutura concorrencial dos canais de distribuição, caracterizado principalmente pelo aumento do poder das grandes redes varejistas. Essas mudanças afetam todos os formatos de varejo, incluindo as grandes redes que atuam nos grandes centros urbanos, e os pequenos supermercados de bairro. Localizados normalmente em bairros mais afastados do centro, e de maior carência sócio-econômica, esses pequenos supermercados são atendidos quase que exclusivamente por distribuidores atacadistas. Dessa forma, o objetivo principal desse artigo é avaliar os relacionamentos comerciais entre os pequenos supermercados, especificamente os do tipo de bairro (localizados em cidades do interior), com seus fornecedores atacadistas. De modo específico pretende-se analisar: o princípio das relações; as características das negociações realizadas e o formato das relações comerciais. Para atender esse objetivo, foram entrevistados os proprietários de 08 supermercados localizados em municípios da região Oeste do Estado de São Paulo (Alta Paulista), considerada a segunda região mais carente do estado.

PALAVRAS CHAVES: canal de distribuição, relacionamento comercial, supermercado de pequeno porte, negociação

ABSTRACT:The retail market is going through changes, demanded by changes in the consumer behavior, seeking more convenience, changes in the economic environment with economic stabilization and changes in the competitive structure of the distribution channels, characterized mainly by increasing the power of large retail. These changes affect all retail formats, including the neighborhoods small supermarkets. Usually located in neighborhoods further away from the downtown, and with higher socio-economic deprivation, these small supermarkets are supported almost exclusively by wholesale. Thus, the main objective of this paper is to assess the commercial relationships between neighborhood small supermarkets (located in inland cities), with its wholesale suppliers. Specifically we intend to examine: the principle of relationship, the characteristics and format of negotiations in trade relations. To meet this objective, we interviewed the owners of 08 supermarkets located in cities of the western region of São Paulo (Paulista High), considered the second poorest region of the state.

KEY WORDS: distribution channels, commercial relationship, neighborhoods small supermarkets

\footnotetext{
${ }^{1}$ Artigo Recebido em 27.09.2010. Revisado por pares em 18.11.2011. Recomendado em 30.11.2011 por Leomar dos Santos Editor. Publicado em 10.02.2012.

Organização Responsável pelo periódico: Universidade regional de Blumenau - FURB - www.furb.br/rn

${ }^{2}$ Universidade Estadual Paulista - UNESP - pigatto@tupa.unesp.br

${ }^{3}$ Universidade Estadual Paulista - UNESP - giusantini@tupa.unesp.br

${ }^{4}$ Universidade Estadual Paulista - UNESP - vitoriajana@yahoo.com.br

5 Os autores agradecem ao apoio financeiro da FAPESP - Fundação de Amparo à Pesquisa do Estado de São Paulo, que permitiu a realização da pesquisa.
}

Revista de Negócios, ISSN 1980-4431, Blumenau, v16, n.4, p.107 - 126, Outubro/Dezembro 2011. 


\section{INTRODUÇÃO}

No contexto de uma economia globalizada, dificilmente os mercados se mantém estagnados por longos períodos. Constantes alterações no tempo e no espaço fazem com que as instituições modifiquem a forma de se relacionar com outras instituições ao seu redor. Essas alterações ocorrem continuamente durante o processo, causando modificações nas estruturas do mercado ao longo do tempo e, por meio de cada mudança, uma nova forma de se relacionar emerge.

Os agentes que estão inseridos nesses mercados precisam acompanhar essas mudanças, adotando novas estratégias competitivas, que lhes garantam a possibilidade de continuar competindo.

No novo cenário econômico, imagina-se que todos os setores estejam interligados, ainda que isso não seja de todo real. Dentro dessa corrente de pensamento, ganha força o princípio de que os elos de uma mesma cadeia produtiva devam estar ao máximo possível interligados, diminuindo assim, as disparidades e os gargalos.

Observa-se então, no novo cenário competitivo, a redução dos relacionamentos do tipo "ganha-perde", onde as partes não trabalham em conjunto e tentam ao máximo 'usurpar-se' dos benefícios que os "parceiros" possam oferecer, não levando em consideração as perdas que o mesmo pode sofrer. Em seu lugar, emerge a percepção de que trabalhar em conjunto pode resultar em uma vantagem competitiva frente aos concorrentes. Ganhos em custo, parcerias, novas estratégias adotadas em conjunto, colocam determinadas organizações em posição privilegiada, estabelecendo-se assim, relações tidas como "ganha-ganha".

Alterações no hábito de consumo da população, uma nova e acirrada estrutura concorrencial, provocada pela concentração nos principais canais de distribuição, faz com que as empresas do setor varejista, por exemplo, juntamente com seus fornecedores busquem formas alternativas de atender ao mercado e aumentar a sua competitividade.

No mercado varejista, em especial o de pequeno porte, algumas alterações nas estruturas de mercado têm modificado as formas tradicionais de relação com os consumidores. O que se observa é o crescente surgimento de redes de lojas de menor porte em locais afastados dos grandes centros. No interior, por exemplo, ganha espaço as redes de pequeno porte, com até cinco lojas, contrapondo-se à presença de grandes redes supermercadistas nos grandes centros. Essas redes se estabeleceram em mercados potenciais, não atendidos em todas as suas necessidades, devido à distância das grandes lojas.

Apesar da consolidação do setor, com poucas redes de grande porte atuando nacionalmente, e redes menores, com atuação mais regional, ainda é possível encontrar pequenos supermercados de bairro. Estabelecimentos em que o proprietário fica atrás do balcão atendendo os clientes do bairro, ainda são importantes nessa nova configuração do varejo nacional. Localizados normalmente em bairros mais afastados do centro, ou de maior carência sócio-econômica, funcionam como agente de ligação entre os consumidores e suas demandas mais urgentes.

Essas lojas, pelo perfil e poder de compra, são atendidas basicamente por distribuidores atacadistas, os mesmos que atendem as pequenas redes. Dessa forma, o objetivo principal desse artigo é avaliar os relacionamentos comerciais entre os pequenos 
supermercados, especificamente os do tipo de bairro (localizados em cidades do interior), com seus fornecedores atacadistas. De modo específico pretende-se analisar: o princípio das relações; as características das negociações realizadas e o formato das relações comerciais.

Para isso, foram entrevistadas lojas localizadas na região da Alta Paulista, uma das regiões de maior carência sócio-econômica do estado de São Paulo, e por isso mesmo, de reduzida importância para as grandes redes varejistas.

Este artigo foi desenvolvido em 05 partes, incluindo essa introdução. No item dois, foi realizada a revisão bibliográfica a respeito de canais de distribuição, onde os pequenos varejos estão inseridos, e negociação no canal de distribuição. No item três é apresentada a metodologia utilizada para o levantamento das informações, seguido do item quatro, onde são apresentados os resultados. Finalmente, no item cinco, são feitas as considerações finais.

\section{METODOLOGIA}

Segundo Yin (2001), a maior diferença das pesquisas em áreas sociais está na natureza do fenômeno estudado, uma vez que é mais difícil para explicar, predizer e controlar situações que envolvem os seres humanos e suas reações. $O$ fato de a pesquisa necessitar da interação com indivíduos e organizações onde as pessoas estão inseridas, faz com que surja um grande número de variáveis, advinda das diferentes perspectivas individuais das pessoas que fazem parte da empresa e, até mesmo, da cultura da empresa.

Por envolver relações entre agentes, em um ambiente de constantes mudanças, cria-se dificuldade em generalizar ou replicar decisões, o que conduz a pesquisa a se direcionar no sentido da utilização de métodos qualitativos. Nos métodos qualitativos são poucas as medidas, sendo que a maioria das inferências se desenvolve em função do conhecimento ou experiência que as pessoas têm sobre um produto, serviço, ou uma determinada situação.

Nessas análises, as informações (dados) entram basicamente em forma de palavras, e não em números, e a avaliação desses dados tende a ser mais subjetiva, uma vez que o pesquisador busca estabelecer relações entre as informações coletadas e os modelos que ele interpreta. O método qualitativo se caracteriza por um maior foco na compreensão dos fatos e interpretação dos aspectos do comportamento humano, do que em sua mensuração, ao contrário dos métodos quantitativos, que se preocupam com a medida dos fenômenos e que utilizam amostras amplas e informações numéricas (MARCONI e LAKATOS, 2004).

Esses métodos visam a compreensão ampla do fenômeno que está sendo estudado, tendo como objetivo principal o processo desenvolvido, e não simplesmente, o resultado alcançado. Dessa forma, o método utilizado inicialmente foi o de pesquisa exploratória, com a realização de levantamento bibliográfico (revisão teórica) das teorias que deram suporte à pesquisa, como a abordagem de Canais de distribuição

A pesquisa qualitativa tem se mostrado uma alternativa para a investigação científica, porque é útil para firmar conceitos e objetivos a serem alcançados e dar sugestões sobre variáveis a serem estudadas com maior profundidade. Os métodos qualitativos apresentam uma mistura de procedimentos de cunho racional e intuitivo, capazes de contribuir para melhor compreensão dos fenômenos (GIOVINAZZO, 2001).

Como o objetivo da pesquisa era avaliar comportamentos e ações desenvolvidas nas relações comerciais entre as empresas, os dados obtidos foram resultado da impressão que os 
entrevistados possuíam da relação comercial em discussão. Dessa forma, optou-se pelo estudo de caso, a partir de uma amostra intencional de redes varejistas, que atuam no setor supermercadista.

O estudo de caso envolve a análise intensiva de um número relativamente pequeno de situações, dando-se ênfase à completa descrição e ao entendimento das relações entre os fatores observados em cada situação. Deve ser utilizado para explicar, descrever, avaliar e explorar situações, quando a questão de pesquisa é do tipo "como" e "por que", e o investigador tem pouco ou nenhum controle sobre o evento (YIN, 2001).

No caso dessa pesquisa, o "como" é importante para se compreender a visão que os pequenos varejos possuem em relação ao seu relacionamento comercial com os fornecedores atacadistas. O "por que" ajuda a descobrir os motivos que levaram as empresas a adotar tal comportamento em relação aos seus parceiros comerciais.

Este trabalho possui como foco de análise nas empresas varejistas situadas na região da Alta Paulista, interior do Estado de São Paulo. São empresas de pequeno porte, especificamente, pequenos supermercados de bairro, que realizam suas compras com atacadistas de produtos de mercearia básica. Apesar de localizado no estado mais rico do país, a região possui baixos indicadores de emprego e renda, sendo que 12 municípios da região (de um total de 30 municípios) se situam entre os 100 municípios com menores Índices de Desenvolvimento Humano (IDH) do estado (PNUD, 2001).

Com essa característica, a região possui dificuldade em atrair as grandes redes varejistas, que necessitam de um maior volume de vendas para obter lucro. Ao mesmo tempo, torna-se uma região atrativa para o desenvolvimento de pequenas redes regionais, e principalmente supermercados de bairro. Supermercados onde o consumidor pode fazer suas compras e pagar apenas no final do mês, ou quando tiver disponibilidade de recursos.

Apesar de contraditório, uma vez que as grandes redes possuem melhores condições de arcar com prejuízos momentâneos (fiado) dos consumidores finais, são os pequenos supermercados de bairro que possuem essa característica e que tornam-se referência para o consumidor de menor renda. Essas empresas de pequeno porte têm alcançado um grande destaque no cenário do varejo, ao contrário das grandes lojas localizadas nos grandes centros urbanos, que tem enfrentado uma maior concorrência e uma conseqüente redução de lucros e receitas. O perfil das empresas com porte semelhante das analisadas é de baixo investimento em marketing e propaganda, o que lhes permite em determinados momentos oferecer produtos com preços acessíveis a seus consumidores, atraindo-os cada vez mais.

Foram selecionadas oito empresas da região, todas com até três check-outs ${ }^{6}$, onde cada um dos entrevistados é atendido em média, por quatro fornecedores atacadistas, podendo este número variar a cada semana. Os fornecedores atacadistas identificados pelos distribuidores estão localizados em Minas Gerais, e em cidades com tradição no setor atacadista, como Presidente Prudente e Ribeirão Preto.

Nenhuma das empresas entrevistadas fazia parte de Centrais de Compras ou redes organizadas patrocinadas pelas redes atacadistas, como o caso da Rede Smart (Atacadista Martins) ou Rede Valor (Grupo Peixoto). Caracterizam-se assim, como pequenos

\footnotetext{
${ }^{6}$ Segundo classificação utilizada pela Associação Brasileira de Supermercados (ABRAS), supermercados com até 4 check-outs são classificados como Lojas de Conveniência e/ou Lojas de Proximidade.
} 


\section{RELACIONAMENTO COMERCIAL EM CANAIS DE DISTRIBUIÇÃO: ANALISE SEGUNDO OS PEQUENOS SUPERMERCADOS DE BAIRRO}

supermercados de bairro, sem assessoria financeira ou gerencial de um atacadista, com apenas 1 loja, e público focado nas classes C e D. Essas empresas foram selecionadas de maneira aleatória, a partir de listas fornecidas pelos Sindicatos de Comércio Varejistas das cidades da região estudada.

Após o contato inicial e algumas reuniões com os proprietários, foi possível aplicar o questionário e analisar a maneira como que as mesmas se relacionam comercialmente com seus fornecedores atacadistas. Para colaborar com a ética acadêmica e com o acordado com os varejistas, as empresas estudadas não serão discriminadas ou identificadas em nenhum momento do artigo. Assim sendo, a união dos dados configura a característica dessas relações como um todo, e não parcialmente de cada relacionamento de cada empresa.

\section{REVISÃO TEÓRICA}

\subsection{Canal de Distribuição}

A adoção do conceito de Supply Chain Management (SCM) ou Gestão da Cadeia de Suprimentos está se tornando, no atual modelo econômico, o mecanismo principal para a integração de processos de negócios entre consumidores finais e fornecedores, para que se busque a competitividade e a rentabilidade das empresas envolvidas (GUNASEKARAN et al., 2001). Porém, é importante destacar, conforme apontou Spekman et al. (2002), que muitos gestores ainda pensam na SCM apenas como um mecanismo de redução de custos. O interesse das empresas pela gestão da cadeia de suprimento vem aumentando continuamente desde os anos de 1980, quando elas perceberam que haveria benefícios oriundos de relações mais colaborativas dentro da organização.

Nas atuais cadeias de suprimento, os participantes são os mesmos das cadeias tradicionais, mas as regras do jogo mudaram e os papéis e as responsabilidades de cada membro não são mais baseados em funções tradicionais (comprar, vender ou entregar um produto), mas sim, em responsabilidades (a empresa com melhor desempenho na execução de determinada tarefa torna-se responsável por ela). Dessa forma, por exemplo, o fornecedor pode se tornar responsável pelo lay out de determinado espaço dentro da loja de um distribuidor. Ao contrário das cadeias tradicionais, os papéis e responsabilidades dos participantes tornaram-se fluidos, dinâmicos e voltados para o consumidor (BLACKWELL, 2001).

Segundo Beamon (1999), uma cadeia de suprimentos pode ser analisada como um conjunto de processos integrados, que engloba todos os elos da cadeia que estão fortemente conectados. Esses processos englobam desde os fornecedores da indústria (produtor rural ou outra indústria), os fornecedores de insumos, a indústria de apoio, os distribuidores e outros agentes por meio dos quais matérias-primas são manufaturadas em produtos finais e chegam ao alcance dos consumidores.

Fundamentada no princípio de que deve haver ganho conjunto entre todos os membros participantes, a partir da demanda criada pelo consumido final, a gestão da cadeia de suprimentos pode ser dividida em duas partes: uma relativa à gestão de suprimentos e que diz respeito ao gerenciamento das relações entre a indústria processadora e seus fornecedores de 
insumos, e outra, à gestão da distribuição, que trata das questões entre a indústria manufatureira e seus distribuidores.

No caso em que o objeto de estudo são as relações entre os atacadistas e seus distribuidores, torna-se necessário focar a análise nos canais de distribuição, cujo escopo está centrado nas relações que fazem o produto chegar ao consumidor final, a partir da indústria processadora, passando por distribuidores atacadistas e varejistas. A identificação dos agentes que estão situados dentro de um canal de distribuição é dada pela característica de posse do produto.

O conceito de Canal de Distribuição, assim como o de Gestão da Cadeia de Suprimentos, está fundamentado em alguns princípios básicos, em que toda a estratégia, as decisões e as ações decorrentes destas são tomadas considerando o seu efeito no canal como um todo, não havendo funções ou organizações independentes, e sua estrutura consiste em organizações e pessoas para que as estratégias possam ser implementadas.

As alterações observadas no comportamento do consumidor e nas estratégias dos agentes (fornecedores e distribuidores) que estão diretamente ligados a eles, estão promovendo alterações importantes na arquitetura de muitos canais de distribuição. Esses canais estão revendo suas fronteiras e formas de atuação, levando a mudança nas competências e modificando a forma de relacionamento com seus fornecedores. Assim, segundo Rosenbloom (2002), um canal de distribuição transfere as mercadorias dos fabricantes para os consumidores, preenchendo as lacunas de tempo, local e posse que separam as mercadorias e serviços daqueles que as necessitam ou desejam, servindo como um mecanismo de articulação, em que estão presentes também outros tipos de fluxos.

$\mathrm{Na}$ área de marketing, o termo Canal de Distribuição já se encontra fundamentado e consolidado com conceitos bem definidos. Trabalhos relevantes, como Alcântara (1997), Neves (1999), Silva (1999) e Pigatto (2005) utilizam, em sua maioria conceitos atribuídos a Bowersox e Cooper (1992), Stern et al. (1996) e Berman (1996). Esses conceitos apresentam como linha principal a identificação da relação entre organizações interdependentes, o compartilhamento de objetivos comuns e o processo de tornar produtos e serviços disponíveis para uso e consumo.

Dessa forma, canais de distribuição podem ser definidos como um conjunto de organizações - agentes e instituições - que se relacionam com o objetivo de tornarem produtos e serviços disponíveis, buscando criar valor ao consumidor pela aquisição e disponibilidade de produtos e serviços (BERMAN, 1996; PELTON, et al. 1997; COUGHLAN et al. 2002; ROSENBLOOM, 2002).

Para compreender o funcionamento dos elos que compõem um canal de distribuição, também é necessário ter conhecimento dos elos que o compõem. O setor atacadista é um dos principais intermediários existentes nesse percurso, servindo como um veículo de chegada dos produtos aos mais diversos e específicos mercados. Em países como o Brasil, onde a infraestrutura ainda é considerada precária em relação aos países desenvolvidos, o atacado desempenha um papel de grande importância. Em 2009, o setor atacadista brasileiro faturou aproximadamente R\$ 130 bilhões de reais, o que representa participação de $50 \%$ no abastecimento do varejo nacional, e $5 \%$ do PIB brasileiro. (ABAD, 2010). O atacado pode ser 

RELACIONAMENTO COMERCIAL EM CANAIS DE DISTRIBUIÇÃO: ANALISE
SEGUNDO OS PEQUENOS SUPERMERCADOS DE BAIRRO

considerado um agente de distribuição a lojas menores e localizadas em regiões distantes dos grandes centros, onde não haveria possibilidade ou interesse de acesso por parte da indústria.

Segundo o Ranking ABAD/Nilesen, 95\% dos supermercados pequenos - de um a quatro checkouts - são abastecidos por empresas atacadistas distribuidoras, sendo que o pequeno e o médio varejo são os que mais atendem os consumidores das classes $\mathrm{C}, \mathrm{D}$ e $\mathrm{E}$ (ABAD, 2010).

O último elo a ter contato com o consumidor final, e que o abastece diretamente, é o varejo. Pode ser considerado como toda e qualquer atividade que ofereça diretamente ao consumidor final, por meio da aquisição da indústria e/ou atacado, produtos ou serviços. É o elo mais sensível às alterações do mercado, o que possui o maior contato com o consumidor e com suas necessidades e desejos.

Em 2009, o setor de supermercados faturou R $\$ 177$ bilhões de reais, ultrapassando 78 mil lojas, sendo que apenas 20 das mais de 60 mil empresas do setor no país faturam mais de R\$ 500 milhões/ano (ABRAS, 2010).

A idéia cada vez mais generalizada de que a estratégia das empresas é baseada nos desejos do consumidor faz com que este tenha importância no fluxo de negociação entre distribuidor e fornecedor. O que significa que o consumidor é influenciado pelos elos anteriores, porém, também, possui poder de influência. Dessa forma, fica evidente a importância estratégica do canal de distribuição no desenvolvimento da empresa, independentemente do ramo de atuação.

Estruturar um canal de distribuição é um esforço conjunto e coordenado de agentes que compartilham de objetivos comuns. Desse modo, a gestão eficiente do relacionamento entre os elos é um elemento importante para a integração do canal de distribuição, tornando a estabilidade e a eficiência no gerenciamento do relacionamento pré-requisitos essenciais para o sucesso da parceria.

Segundo Rosenbloom (2002), apesar da abordagem de níveis do canal permitir obter uma idéia dos tipos de participantes e em qual nível o participante se encontra, ela, porém não permite definir explicitamente a estrutura do canal e, principalmente, não consegue definir a relação entre esta estrutura e a gestão do canal.

A necessidade de se conseguir estabelecer as relações de um canal de distribuição é de extrema importância, em razão do que Rosenbloom (2002) chamou de dimensões comportamentais. Segundo esse autor, o canal não é simplesmente um sistema econômico racionalmente ordenado, desprovido de processos e interações sociais, mas sim, um sistema social sujeito aos mesmos processos comportamentais que são característicos de todos os sistemas sociais. Com isso, segundo o referido autor, as dimensões comportamentais fundamentais presentes em todos os sistemas sociais - conflito, poder, papel e processo de comunicação - acabam fazendo parte das relações comerciais.

Segundo Chen et al. (2004), dentro do paradigma colaborativo, as relações comerciais são compostas por redes de relacionamentos interdependentes, desenvolvidas e promovidos com a colaboração estratégica de todos e com o objetivo de obter benefícios mútuos. Hakansson e Snehota (1995) discutem o processo do "networking", apontando que a dimensão mais importante da mudança em redes de negócio está no desenvolvimento das 
atividades de ligação, dos recursos envolvidos e das ligações entre os agentes envolvidos no relacionamento.

Além disso, no atual estágio de concorrência entre as empresas e na necessidade de atender a diferentes mercados, uma empresa participa de diversos canais de distribuição. Ao mesmo tempo, segundo Cooper et al. (1997) e Silva (1999), dificilmente uma empresa mantém relações próximas ou de parceria com todos os elos ou pontos da cadeia. Sempre existirão fornecedores e clientes preferenciais que ocasionarão diferenças importantes no tratamento de cada componente ou atividade do canal de distribuição.

\subsection{Negociação no Canal de Distribuição}

A relação entre o distribuidor e o fornecedor é bastante complexa, havendo simultaneamente interesses comuns e uma série de conflitos. É consenso que fornecedores e distribuidores são parceiros no objetivo de disponibilizar uma mercadoria para o consumidor final, e para isso, é necessário que exista uma negociação transparente entre os dois lados. Entretanto, as empresas não podem deixar de lado seus objetivos individuais, ou seja, os resultados operacionais que as mantêm competitivas e no mercado.

A complexidade da relação entre varejo e fornecedor pode ser atestada por Parente (2000), que colocou o processo de compra do varejista como a atividade mais crítica da empresa, pois, à medida que as vendas são realizadas, o estoque necessita ser reposto, para que o consumidor tenha acesso ao produto e este possa ser vendido. Porém, a empresa não pode esperar que o estoque baixe para ir atrás do fornecedor (atacado ou indústria) para negociar uma nova compra. Da mesma forma, o fornecedor não pode ficar esperando que o comprador (varejista) venha até ele toda vez que falte produto nas suas gôndolas. Caso esse cenário ocorra, a perda é evidente para ambos os agentes. Para o distribuidor, principalmente o fabricante, porque seu produto não estará na gôndola e o consumidor não irá comprá-lo e, para o varejista, porque sem o produto na gôndola o consumidor deixará de ir até sua loja e passará a comprar em outros estabelecimentos.

Entretanto, independente do setor ou área de atuação, é normal que as empresas adotem estratégias de ganhos (lucros) máximos, e essa estratégia passa, necessariamente, pela obtenção de ganhos a partir de perdas dos concorrentes. Os ganhos do distribuidor varejista, por exemplo, advêm do aumento da sua receita, obtido do aumento do volume de produtos vendidos ou do aumento do preço do produto. Porém, o consumidor atual faz compras em quantidades menores, para atender a uma demanda imediata, fazendo com que o varejista tenha maior dificuldade em conseguir aumentos no volume de produtos vendidos. A possibilidade de o consumidor obter diversos produtos em diferentes pontos de venda, como padarias, açougues, lojas de conveniência, lojas de vizinhanças, bares, varejões e até mesmo em farmácias, faz com que o aumento de preços não seja uma alternativa eficaz para o varejista.

Da mesma forma, os distribuidores atacadistas têm dificuldades de aumentar seu ganho por meio do aumento dos preços ou da venda de volumes maiores, uma vez que as 
pequenas redes de varejo, tradicionais clientes, estão formando Centrais de Compra $^{7}$ e adquirindo seus produtos diretamente das indústrias. ${ }^{8}$ Ao mesmo tempo, algumas indústrias estão vendo as redes varejistas de porte médio como um novo mercado a ser desenvolvido.

Essa atuação, baseada no objetivo individual da maximização do lucro, leva a uma relação conflituosa entre distribuidores e fornecedores, uma vez que o distribuidor deseja comprar o produto pelo menor preço possível e o fornecedor deseja vender pelo preço que atinja sua lucratividade máxima.

O canal de distribuição serve como um espaço onde, em um sistema de livre mercado, várias empresas ligadas por uma relação de oferta e demanda realizam a transferência de propriedade de produtos e serviços, podendo ser caracterizado como um campo de batalha onde se decide o sucesso ou o fracasso da empresa (ARNOLD, 1999; BOWERSOX e CLOSS, 2001). Isso pode ser confirmado por meio de observações do mercado, em que um comerciante pode se abastecer de produtos similares ou substitutos de diversos fornecedores. Já o fornecedor tem à sua disposição, no mercado, diversas empresas comerciais com estrutura e interesse em oferecer seu produto.

Fornecedores e distribuidores estão realizando constantemente operações comerciais. Essas operações tradicionalmente se transformam em benefícios imediatos para um dos envolvidos e, conseqüentemente, em desvantagens para o outro envolvido, de acordo com seu poder de negociação ou da situação em que a operação ocorre. Assim, negociações agressivas, em que um dos lados acaba assumindo uma posição mais intransigente, objetivando tirar proveito de uma conjuntura momentânea, podem se transformar em dificuldades futuras quando esse mesmo lado necessitar de ajuda do seu parceiro.

Esse tipo de operação caracteriza um contrato clássico do mercado, em que, segundo Coughlan et al. (2002) é possível identificar algumas características: os acordos não prevêem compartilhamento (de risco, experiência etc.); não existem distinção nem continuidade; os agentes são intercambiáveis e lidam uns com os outros de maneira completamente independente e impessoal; negociam cada transação como se fosse a única e; começam e terminam suas transações com base somente nos méritos correntes do conjunto de ofertas.

\section{ANALISE DOS RESULTADOS}

Os resultados apresentados representam a opinião dos proprietários dos supermercados de bairro em relação ao tratamento recebido dos seus fornecedores atacadistas. O item está estruturado em três sub-itens, sendo o primeiro, referente ao princípio das relações comerciais entre esses agentes (como se iniciam as relações). O segundo sub-item relata a negociação entre as partes, e o terceiro sub-item, o formato das relações comerciais entre os dois agentes. Ao final do terceiro sub-item é apresentado um quadro resumo (quadro 1), com as principais características observadas pelos agentes entrevistados.

\subsection{A Relação}

\footnotetext{
${ }^{7}$ Modelos de associativismo que têm, entre outras funções, a compra conjunta, elaboração de promoções e divulgação conjunta, padronização das lojas, treinamentos, pesquisa de preços e do consumidor.

${ }^{8}$ Tanto no caso das redes varejistas, quanto das redes atacadistas, as receitas também estão sendo majoradas por meio do oferecimento de serviços que atraem os consumidores e buscam criar fidelidade.
} 
Para compreender a maneira como os pequenos varejistas analisam as suas relações comerciais em um determinado mercado, torna-se necessário compreender como funciona/ ocorre essa relação comercial. A primeira característica de destaque, encontrada no varejo de pequeno porte é a forma como as relações se iniciaram, uma vez que, do universo entrevistado, em apenas $12,5 \%$ dos casos o varejista foi responsável pela iniciativa de procurar o atual atacadista principal para iniciar a relação de compra e venda. Essa procura pelo fornecedor ocorreu em função de informações obtidas e dos preços oferecidos, sendo que as vantagens oferecidas eram satisfatórias, a ponto de valer a pena procurá-lo e iniciar uma negociação.

Os demais entrevistados foram procurados pelos atacadistas em seus estabelecimentos. Segundo relato dos varejistas, mensalmente, pelo menos um novo fornecedor atacadista tenta iniciar uma relação experimental, oferecendo preços baixos e produtos novos. Normalmente, a proposta do atacadista é de que inicialmente o distribuidor varejista faça um teste com o produto ou produtos por um mês, e caso o serviço prestado se mostre insatisfatório, o varejista pode descartar esse fornecedor da sua carteira, sem maiores transtornos.

A grande concorrência existente entre os fornecedores atacadistas leva à necessidade de os mesmos oferecerem ganhos financeiros imediatos para o distribuidor. Este é o fator de maior importância para os varejistas e o que possui maior peso na hora de realizar a escolha do parceiro e efetuar a compra.

Quando questionados sobre qual seria a razão principal em iniciar a relação, os varejistas deixaram clara a importância que o preço representa como variável determinante na escolha do fornecedor. Para eles, os preços baixos são a única variável que pode lhes oferecer competitividade diante da concorrência com outros varejos (de mesmo porte ou não), uma vez que eles não dispõem de recursos (propaganda, panfletos, enxovais) desfrutados por lojas maiores. Sendo assim, tudo começa com uma oferta de preço menor que a do concorrente.

Nessa procura por novos clientes, o maior trunfo dos atacadistas é de fato reduzir os preços dos produtos ofertados, dispondo-os abaixo da concorrência. Os produtos mais vendidos, como os componentes da cesta básica, por exemplo, chegam a ser oferecidos no primeiro contato, com valores até $40 \%$ mais baixos que os de outros atacadistas.

Essa estratégia utilizada pelos atacadistas possui um limite, um ponto no qual o atacadista está disposto a chegar para que se estabeleça uma relação firme com o distribuidor. Esse limite se baseia nos custos dos atacadistas e no risco da queda dos lucros. Dessa forma, os atacadistas se organizam para conviver com o risco por um determinado período, na tentativa de firmar uma relação que possa lhe assegurar benefícios futuros.

Em situações onde há grandes diferenças de preço, ocorre a desconfiança por parte do varejista. Em alguns casos, a vantagem em preços oferecida pelos atacadistas é temporária, e passado determinado período de tempo, os preços sobem superando inclusive os preços dos produtos ofertados pelos fornecedores substituídos. Nesses casos, a iniciativa dos varejistas é selecionar e comprar com um mesmo fornecedor apenas os produtos com menor preço, diminuindo assim, o lote de compra, e aumentando o número de empresas com as quais se relaciona. Em outros casos, a solução é trocar de fornecedor atacadista freqüentemente, até que o preço volte a ficar satisfatório. 


\section{RELACIONAMENTO COMERCIAL EM CANAIS DE DISTRIBUIÇÃO: ANALISE}

SEGUNDO OS PEQUENOS SUPERMERCADOS DE BAIRRO

A opção por se relacionar com um número maior de fornecedores é utilizado pelos pequenos supermercados como uma estratégia defensiva, frente à possibilidade de ficar na mão de poucos fornecedores. Mesmo que a estratégia de focar em poucos fornecedores e, conseqüentemente, de adquirir volumes maiores destes, possa resultar em preços melhores no momento da negociação.

O que se observa nesses casos é uma estratégia que visa benefícios momentâneos e uma falta de parceria entre os agentes. $\mathrm{O}$ atacado visa apenas diversificar sua carteira de clientes e diluir seu risco. Para isso, usa os preços baixos como atrativo, aumentando-os gradativamente após determinado período. Não há nenhuma ação das partes para que a relação tenha continuidade ao longo do tempo. Ambas as partes saem prejudicadas, pois o atacadista perde um cliente, e o varejista tem o custo de comprar de mais um fornecedor.

Como a estrutura de preços é sempre repassada ao consumidor, este é o maior prejudicado da relação, já que em uma determinada data pode adquirir os produtos a um determinado preço, entretanto, após algum tempo, o preço pode ter subido consideravelmente. Estas oscilações, na maioria dos casos, tornam o consumidor descontente, e gera desconfiança entre o mesmo e o varejista, resultando neste caso, na perda de fidelidade do consumidor.

Em relação ao perfil dos clientes das lojas varejistas analisadas, estes são fixos, como moradores do bairro, de sítios, clientes com conta em aberto, amigos e outros que possuem o hábito de realizar as compras do mês em apenas um supermercado. Neste caso, desvantagens nos preços oferecidos podem ocasionar a migração desses clientes para outros supermercados existentes, ocorrendo assim, a perda de competitividade do varejista.

Apesar desses fatores serem preponderantes em uma relação de mercado, onde há grande concorrência, a forma como se inicia e se estabelece a relação entre atacadistas e varejistas têm se mantido inalterada ao longo do tempo. Para que se estabeleça uma relação de longo prazo entre o varejista e seu principal fornecedor, é necessário que os preços se mantenham atrativos de forma constante, uma vez que perceber uma alteração significativa nos preços já é ação suficiente para que o varejista abandone a relação.

Além de um preço constante, a confiança e o comprometimento firmados ao longo do tempo também são preponderantes no prosseguimento da relação. Unidos ao preço, esses são os diferenciais que fazem com que os varejistas optem por um ou outro fornecedor. Relações de amizade estabelecidas ao longo do tempo contam pontos para o andamento da relação, sendo variáveis de extrema importância, mas que na concepção dos varejistas, estão em segundo plano, sempre atrás dos preços mais baixos.

A pontualidade na entrega, um histórico de produtos sem defeito e baixo nível de desvio de carga são variáveis interpretadas pelos varejistas como sinal da relação de confiança e comprometimento do atacadista, e que leva o varejista a manter o fornecedor em sua carteira por período maior. Se seus preços são os mais competitivos, esse passa a ocupar o lugar de principal fornecedor.

Entretanto, mesmo quando essas variáveis pesam na confiança desse varejista, ao observar que os preços subiram, a iniciativa do varejista é diminuir o tamanho do lote na próxima compra, ou substituir esse fornecedor de confiança por outro que lhe ofereça os preços mais baixos naquele momento. 
É imprescindível destacar que nesse tipo de relação a substituição de um fornecedor ocorre de maneira rápida e fácil, uma vez que não existem contratos que dominam as relações analisadas. A não existência de contratos de fornecimento é comum entre as partes que se relacionam no pequeno varejo, uma vez que a negociação ocorre semanalmente, e apenas sobre um lote determinado, sem planejamento futuro.

\subsection{Negociação}

Semanalmente, os representantes de venda dos atacadistas que atuam na região passam nos supermercados deixando uma cópia das cotações de preço dos seus produtos. Isso inclui as lojas onde o atacadista ainda não é fornecedor, na tentativa de iniciar uma relação comercial. Essa atividade ocorre em um dia determinado da semana, normalmente quarta ou quinta-feira, sendo o pedido do lote acordado no dia seguinte.

A existência de diversos fornecedores é de conhecimento mútuo, da mesma forma, o fato de que o varejista irá decidir, a partir dessa cotação, com quem irá adquirir, quais tipos de produtos e em qual quantidade. Em alguns estabelecimentos ocorre o que é conhecido no ramo como "pinga-fogo".

Todos os vendedores se reúnem em um estabelecimento (normalmente aquele que possui maior volume de compras), aguardam a análise do varejista e negociam a reavaliação dos preços de determinados itens desejados. Nessa reunião, há uma disputa entre os fornecedores para ver quem obtêm o maior lote de compras.

A reunião é normalmente marcada pelo varejista em um dia da semana de sua escolha, sendo que em alguns estabelecimentos esse dia é igual em todas as semanas. Não existe organização prévia da reunião, com pauta e seqüência. Os atacadistas interessados em fornecer para aquele estabelecimento comparecem no horário estabelecido e tentam vender seus produtos ao mesmo tempo.

Observou-se que este tipo de negociação ocorre em apenas 25\% dos casos analisados; em estabelecimentos que possuem um histórico de compras considerável para o fornecedor, maior número de check-outs e maior poder de compra. Nestes casos, existe uma atenção maior do atacadista para com o estabelecimento, podendo ser verificado no fato de reconsiderar o preço fixado na cotação, demonstrando maior flexibilidade entre as partes.

Esse procedimento ocorre apenas nos varejistas mais organizados e com volume de vendas representativo na carteira de clientes do representante. $\mathrm{O}$ fato de o varejista ser um formador de opinião entre seus pares, também pode servir de estímulo para uma disputa entre os representantes.

Nos demais casos, o contato do vendedor limita-se à entrega da cotação de preço de seus produtos em uma visita breve, sendo que dúvidas e pedidos são realizados em uma conversa informal entre ambos. Nos casos onde existe amizade entre vendedor e varejista, o bom relacionamento influencia as negociações. A concessão de descontos pode ocorrer, desde que o benefício seja mútuo, ou seja, o varejista se compromete a comprar um lote maior, beneficiando a comissão que o vendedor recebe por suas vendas, e este se compromete a conceder um desconto também considerável ao varejista na compra de determinados itens.

Uma vez recolhidas as cotações deixadas pelos vendedores, os varejistas irão comparar os preços dos itens dentro das seções de produtos, por exemplo, produtos de 

RELACIONAMENTO COMERCIAL EM CANAIS DE DISTRIBUIÇÃO: ANALISE
SEGUNDO OS PEQUENOS SUPERMERCADOS DE BAIRRO

higiene, limpeza, beleza e alimentos não perecíveis. Comparados os preços dos fornecedores, o próximo passo é confrontar com o preço ofertado anteriormente pelo mesmo atacadista (essa comparação permite ao varejista verificar a diferença existente entre as cotações ao longo do tempo). Se o preço de um item sobe na maioria dos atacadistas, tal fato pode ser justificado por um acontecimento de mercado, aumento do preço das matérias primas, ou variação climática. Entretanto, se um item sofre elevação de preços de forma individual, em um atacado, não há justificativa aparente. Depois de realizada essa comparação de preços, o comerciante decide como irá realizar a compra dos lotes.

Faz-se necessário lembrar que existe a peculiaridade de cada cliente com seus produtos. O varejista preocupa-se, no momento de efetuar o pedido, em adquirir itens que normalmente são os mais vendidos, preferidos pelos seus clientes. Ainda que haja variação nos preços, existem produtos que são inelásticos, ou seja, não sofrem grandes alterações em sua demanda com as mudanças de preço. São esses produtos que oferecem ao varejista a segurança de que serão vendidos.

O lote de produtos a ser adquirido pelo supermercado é separado em grupos (pacotes), onde se reúne todos os itens que um mesmo atacadista oferece a um preço competitivo (menor preço). Separados os itens, é efetuado um pedido de compras para cada um dos fornecedores, de acordo com os preços oferecidos (independente se são categorias similares ou não), de forma que cada lote de compra é efetuado com um fornecedor diferente.

Além da busca por menores preços de revenda, a compra de insumos com diferentes fornecedores comprova a falta de confiança existente entre os agentes. Quando uma carga atrasa, não atrasam apenas alguns itens pedidos, mas todo o pedido. Comprar com apenas um fornecedor resultaria em correr o risco de não receber seus produtos no momento esperado, uma vez que os atrasos são constantes no relacionamento com a maioria dos atacadistas. Assim, distribuir os lotes entre fornecedores diferentes seria diluir o risco de ficar sem produtos para revenda na prateleira.

Como característica do porte das empresas que formam este tipo de varejo, as mesmas não dispõem de espaço disponível para estoques de médio/longo prazo, utilizando a maior parte do espaço disponível para a exposição dos produtos. Muitas vezes, o lote exposto para a venda é formado por todo o volume adquirido pelo varejo.

Dessa forma, não há uma negociação com o principal fornecedor, de maneira que ambos possam chegar a um consenso quanto ao tamanho do lote, seu preço ou data de entrega dos produtos. As duas partes já estão acomodadas com esta forma de negociação.

Ações como, ofertar descontos ou serviços ao varejista para que este faça a compra de um número maior de itens, ou até mesmo, prazo maior para pagamento, não são tomadas por parte do fornecedor. O varejista, por sua vez, não se compromete a realizar compras subseqüentes ou maiores com um mesmo fornecedor, sob nenhuma hipótese. Semanalmente, o fornecedor principal pode ser surpreendido no tamanho do lote requisitado (aumento ou redução do volume em relação à semana anterior).

Mais uma vez é possível observar desvantagens para ambas as partes. Nos relatos dos entrevistados, ficou claro que não há a percepção de maiores benefícios em adquirir os produtos de apenas um fornecedor, ou com um número menor de fornecedores. 
Quando questionados sobre a possibilidade de um acordo, como por exemplo, aumentar o lote de compras de um mesmo fornecedor, diminuindo os lotes fracionados dos demais, houve grande resistência na percepção dos benefícios da ação. O medo de se arriscar é grande, e não há nenhum tipo de segurança em dar o primeiro passo para o estreitamento da relação, pelo contrário, em $100 \%$ dos casos há a presença de grande insegurança, além do risco de perder competitividade diante da concorrência. Esta insegurança, somada à indiferença por parte dos atacadistas diante das oscilações no tamanho dos lotes semanais, colabora muito para que a relação se mantenha inalterada.

Atitudes como cobertura de preços do concorrente, suporte comercial, suporte de vendas, ouvidoria de reclamações com rápida resposta para correção de problemas, entre outras, não são oferecidas pelos fornecedores, resultando na falta de estratégia de ambas as partes que permita o estreitamento da relação, no sentido do firmamento da confiança e parceria de longo prazo.

Nesse caso, observa-se que a estratégia de venda dos atacadistas muda de rumo, concentrando-se em descontos para supermercados maiores, que têm um giro maior e um prazo de pagamento menor. São eles que dão a maior representatividade nas vendas, apesar de se concentrarem em menor número na região. $\mathrm{Na}$ escala de prioridades, os supermercados de pequeno porte ocupam posição secundária na clientela dos atacadistas.

Com a grande concorrência de atacadistas oferecendo seus produtos, os varejistas obtêm uma pequena vantagem com os atacadistas que oferecem variedades de produtos acopladas a preços baixos. Essa variedade pode consistir em um número maior de marcas de um mesmo produto, o qual o cliente poderá livremente escolher; produtos diferentes, que antes não eram vendidos; e produtos novos no mercado. Um número de itens com maior diversificação é algo almejado pelos varejistas, e que não é freqüentemente oferecido pelos fornecedores.

Muitas vezes os varejistas sofrem com a falta de alternativa na hora de adquirir novos produtos. Existe a pressão por parte dos consumidores finais em adquirir esses produtos, normalmente comparando as ofertas realizadas pelos supermercados maiores. Com o conhecimento da demanda por parte dos consumidores, o pequeno varejista solicita ao representante o produto, porém, não necessariamente a resposta obtida junto ao atacado será positiva.

Como eles não têm poder de compra para realizar transações junto à indústria, a alternativa que lhes resta é de fato comprar no atacado. Estes possuem uma variedade limitada de produtos (por exemplo, embalagens com diferentes tamanhos ou sabores) de mercearia básica, oferecendo apenas os mais vendidos e que lhes rendem uma maior lucratividade. Sendo assim, os atacadistas que oferecem produtos novos ou se comprometem em atender pedidos de clientes ganham vantagem na permanência da relação.

Observa-se neste caso, o poder de influência que o consumidor final possui, por meio dos seus desejos, reclamações, e outras ações que influenciam para que a relação permaneça ou se extinga. O consumidor é o agente final que nunca deveria ficar insatisfeito, sendo o agente da cadeia responsável por remunerar todos os demais. Neste caso, a união de forças entre varejo e atacado só vem a agregar valor na permanência da relação. 


\section{RELACIONAMENTO COMERCIAL EM CANAIS DE DISTRIBUIÇÃO: ANALISE}

SEGUNDO OS PEQUENOS SUPERMERCADOS DE BAIRRO

\subsection{Formato das Relações}

Para que ocorra uma troca em um relacionamento entre duas partes, é necessário que haja um acordo entre elas. Esse acordo pode ocorrer de diferentes formas, onde o objetivo maior é fazer com que ambos cumpram o combinado. No que tange ao firmamento do acordo entre as partes estudadas, a ausência de contrato formal, com o comprometimento pelas partes de seus deveres e direitos é observado em todos os casos analisados. A maioria absoluta dos entrevistados realiza suas transações apenas com acordos realizados diretamente com o vendedor representante do atacadista.

A inexistência de contratos formais é comum no ramo do pequeno varejo, e os estabelecimentos costumam agir dessa forma ao firmarem acordo com o atacado. A maioria absoluta dos varejistas entrevistados está convicta de que esta é a melhor maneira de se relacionar com os atacadistas. Nota-se que esta é uma forma bastante diferente do que ocorre em varejo de grande porte, que realiza compras diretamente com a indústria, onde os acordos com direitos, deveres e sanções são normalmente firmados em contratos.

Quando questionados sobre quais seriam as vantagens e desvantagens de não possuir um contrato firmado entre as partes, a percepção, na maioria dos casos, é de existirem apenas vantagens. O motivo alegado para a inexistência do contrato é a liberdade de poder trocar de fornecedor sem sanções ou prévia comunicação. A troca de atacadista em uma determinada semana tem que ser rápida e fácil, de maneira que o varejista possa escolher livremente de quem ele deseja comprar. A inexistência de um contrato que obrigue as partes a cláusulas de exclusividade é considerada como um benefício pelos entrevistados.

Mais uma vez entra em cena o preço ofertado como variável determinante na relação. A maior desvantagem ressaltada pelos varejistas em possuir algum tipo de contrato seria a obrigação de comprar com um fornecedor que oferece preços mais altos diante de outros que ofereçam preços mais baixos. Como o mesmo produto é oferecido por mais de um atacadista, a inexistência de contratos permite ao varejista buscar sempre o menor preço para o produto.

Nota-se um paradoxo entre a concepção de vantagens e desvantagens que os varejistas observam por não possuir contratos. É considerado uma vantagem a facilidade de escolha de melhores fornecedores, que possuem preço mais baixo, entretanto, os problemas ocorridos durante a transação não permitem ao varejista impor alguma forma de sanção, mesmo quando ocorrem com freqüência. Neste caso, uma variável anula a outra, e não ter contrato implica em necessariamente não ter o direito de reclamar sobre algum problema, como atrasos ou produtos com defeito. Atrasos, desvios da carga, entregas incompletas ou erradas, produtos vencidos nas caixas, são encarados como fatos normais ao longo da relação.

Apesar dessas ocorrências, o varejista procura efetuar o pagamento das faturas em dia. Essa postura é decorrência do principal instrumento de compra que o pequeno varejista possui; a sua credibilidade no mercado. Como estes comerciantes são dependentes de prazo para o pagamento das compras, a falta de credibilidade seria altamente prejudicial para sua competitividade no mercado.

Observa-se que a alta dependência de prazo de pagamento deve-se em parte ao baixo giro de capital que estes estabelecimentos possuem, conseqüência do elevado número de clientes que fazem compras mensais e que pagam suas contas no final do mês, comprando no sistema que o mercado avalia como de "fiado". Mesmo que o prazo para o pagamento ajude a 
postergar a dívida junto ao atacadista, até que sejam efetuados os recebimentos por parte dos clientes, o fato de muitas vezes o varejista ter que efetuar o pagamento das compras quinzenalmente, reduz consideravelmente seu capital de giro.

Mesmo com a facilidade em trocar de fornecedor, existem algumas variáveis na relação que fazem com que o varejista esteja atrelado a um mesmo fornecedor, e que pode, não necessariamente, ser a confiança. Substituir um fornecedor que atrasa constantemente a entrega, mas que possui preço baixo, por um fornecedor que entrega na data, mas que possui um preço maior, ainda é considerado desvantajoso para o varejista.

O que se observa é uma adaptação ao problema, com o comerciante estabelecendo superficialmente um estoque que cubra possíveis atrasos da mercadoria (aumentando o volume do pedido), evitando ficar sem produto na prateleira. Esta atitude é observada em apenas $37 \%$ dos casos, sendo que o restante possui dificuldade em função da falta de espaço físico no estabelecimento.

Para o atacadista, a venda realizada em estabelecimentos deste tipo não é representativa a ponto de haver mudanças significativas em seu comportamento. Quando o caminhão deixa o depósito para realizar as entregas, o primeiro ponto de parada é o estabelecimento onde o valor das compras é mais significativo, onde ficará maior parte da carga. Sucessivamente, os próximos pontos de descarga seguem a hierarquia de maior estabelecimento e de proximidade entre supermercados em uma mesma cidade. Por último, ficam os pequenos supermercados, mini-mercados e armazéns, sendo que os horários de recebimentos dos lotes são flexíveis e sem prévia comunicação.

Comportamento semelhante ocorre com a visita dos vendedores, onde o tempo e a negociação são dispostos em hierarquia de poder de compra. O relato da maioria dos entrevistados foi de que o vendedor deve ser atendido tão logo chegue ao estabelecimento, e o tempo de negociação de prazos, preços e descontos dura em média 30 minutos por representante. Com exceção daqueles onde ocorrem rodadas de negociação visando reduzir o preço dos produtos.

O fornecedor atacadista conta com o respaldo da ausência do contrato, não havendo nenhum tipo de ação individual, sanção, por parte dos estabelecimentos, que possa prejudicar a atuação do atacadista. $\mathrm{O}$ que pode ocorrer é o varejista diminuir o lote de compra ou trocar de fornecedor, entretanto, a representatividade de um supermercado de pequeno porte é pequena, e pode ser facilmente substituída por outro estabelecimento.

Quando há um atraso na entrega ou desvio da carga, o produto só chegará ao supermercado na próxima entrega feita pelo atacadista (dia seguinte ou não), uma vez que o caminhão deverá retornar à sua base e corrigir o erro. Houve relatos de atrasos de até sete dias em um estabelecimento, onde a falta do produto na prateleira do varejista, acaba ocasionando perda de vendas. Com isso, a competitividade do supermercado fica prejudicada, com a insatisfação do consumidor que não encontra o item desejado para venda no supermercado.

Apesar das conseqüências oriundas desse tipo de problema, o comportamento de todos os entrevistados é o mesmo, encarando com normalidade a situação, considerando normal o atraso de um a dois dias na entrega, ainda que os produtos faltem na prateleira.

Essa ação resulta na necessidade de adaptação, equilibrando a falta do estoque de segurança com o atraso da carga. Se a carga não chegar no dia esperado, pode faltar produto, 


\section{RELACIONAMENTO COMERCIAL EM CANAIS DE DISTRIBUIÇÃO: ANALISE}

SEGUNDO OS PEQUENOS SUPERMERCADOS DE BAIRRO

porém, se o pedido for feito considerando-se o atraso, e a carga chegar no dia, esta corre o risco de ser estocada em lugares impróprios.

Outra dificuldade enfrentada envolve o ato da negociação entre o comerciante e o representante de vendas do atacadista na disputa pela fixação dos preços dos produtos que serão adquiridos. Existe uma limitação na negociação, onde o vendedor possui a função de determinar a palavra final. Os descontos, por exemplo, são concedidos pelo vendedor no ato da negociação, não cabendo ao varejista, a opção de recorrer da negação a um pedido de desconto, ou outros tipos de consulta, à não ser por meio do próprio vendedor.

A decisão de vender a um preço mais baixo e ganhar uma comissão menor, ou não vender por um determinado preço, cabe apenas ao vendedor. Este toma suas decisões baseando-se em cotas de venda que precisam ser cumpridas a cada período, no caso, uma viagem ou uma semana.

Os varejistas não conseguem perceber a importância do entrosamento entre as partes no ato da negociação e nas estratégias baseadas na troca. $O$ varejista sempre deseja um desconto para o mesmo lote adquirido anteriormente, e não percebe, por exemplo, que o vendedor pode conceder o desconto desejado pelo varejista em troca de um aumento no volume de mercadorias que formam o lote.

Nesse sentido, para redução desses problemas, uma estratégia que tem sido utilizada pelos supermercados de médio porte é a de formação de grupos (centrais) de compra, ou seja, a união entre supermercados de uma mesma cidade ou região formando uma sociedade, onde as aquisições realizadas junto à indústria são feitas em um único lote. Nesse caso, realizada a compra, a carga é entregue em uma central de distribuição, onde deverá ser encaminhada a cada um dos estabelecimentos de acordo com o pedido realizado. O custo dessa estratégia, normalmente, é compensado pelos descontos adquiridos junto às indústrias, uma vez que o tamanho do lote comprado aumenta consideravelmente.

No caso do varejo de pequeno porte, não há nenhum tipo de união ou contato entre os estabelecimentos de uma mesma cidade ou região, pelo menos entre os agentes entrevistados. As ações são tomadas individualmente e parece não haver interesse ou necessidade de saber se a ação dos atacadistas é semelhante no varejo da região.

A opinião dos varejistas entrevistados é de que deveria haver a fixação de um limite de descontos nos preços de alguns produtos, por exemplo, os que são mais vendidos. Assim, a concorrência não seria desleal para o pequeno comerciante. Essa é uma linha de pensamento que se origina na dificuldade, por parte do pequeno varejista, em aceitar a disparidade entre os preços praticados em seu estabelecimento e os preços dos grandes concorrentes. Entretanto, a sugestão de impor barreiras aos preços praticados pelos atacadistas aos clientes que compram grandes lotes de produtos com freqüência dificilmente seria aceita pela indústria.

\begin{tabular}{|c|c|}
\hline & Características \\
\hline Relação & $\begin{array}{l}\text { - normalmente o varejo é procurado pelo fornecedor atacadista; } \\
\text { - tem interesse em ganho financeiro (preço baixo); } \\
\text { - teme aumentos de preço a partir da segunda compra; } \\
\text { - procura não fazer compras concentradas (poucos produtos e maior número de } \\
\text { fornecedores); } \\
\text { - a confiança e comprometimento são importantes, porém ficam em segundo } \\
\text { plano. }\end{array}$ \\
\hline
\end{tabular}




\begin{tabular}{|l|l|}
\hline & $\begin{array}{l}\text { - semanal, com visita dos vendedores atacadistas às lojas; } \\
\text { - diversos fornecedores que oferecem produtos semelhantes ou iguais } \\
\text { (marcas); } \\
\text { - atacadistas fornecem cotação de preços e recolhem pedidos; } \\
\text { - supermercado decide quanto comprar de cada fornecedor com base no preço; } \\
\text { - amizade e benefícios são importantes, porém preço é variável principal de } \\
\text { decisão. }\end{array}$ \\
\hline & $\begin{array}{l}\text { - não existe contrato formal; } \\
\text { - acordos são firmados através dos pedidos de compra; } \\
\text { - observa vantagem ao ter a opção de substituir fornecedor; } \\
\text { - problemas como atrasos na entrega e falhas/defeitos, que são constantes, são } \\
\text { entendidos como parte do negócio; } \\
\text { - procura pagar fatura em dia para manter credibilidade no mercado; } \\
\text { Relação } \\
\text {-prefere comprar de fornecedor com preço menor, mesmo que atrase a entrega. }\end{array}$ \\
\hline pequenos varejos (de bairro) em relação aos seus fornecedores atacadistas
\end{tabular}

Fonte: pesquisa

\section{CONCLUSÃO}

A análise do relacionamento comercial entre os pequenos varejistas e os fornecedores atacadistas de produtos de mercearia básica, a partir do ponto de vista dos pequenos varejistas, leva à conclusão de que estes não possuem a percepção de que a adoção de uma estratégia que una as necessidades das partes pode trazer benefícios para as mesmas.

$\mathrm{O}$ risco ainda assume papel importante nas decisões tomadas, sendo que cada agente quer se prevenir de possíveis perdas. Contudo, uma ação que una as estratégias, diminua o risco, as perdas, e traga competitividade para ambos, é possível. O varejista pode conseguir maiores descontos, enquanto o atacadista pode fidelizar seu cliente por meio desses descontos e aumentar o nível das vendas para um mesmo estabelecimento.

Apesar de existirem barreiras que constantemente dificultam o relacionamento entre os agentes, existe também, de modo disseminado no meio, o reconhecimento do que seria necessário ocorrer para que a relação não fosse tão conturbada. Esses varejistas reconhecem e classificam que confiança, segurança, comprometimento e pontualidade possuem prioridade na escala de importância sobre o que se deve ter em um bom relacionamento com o fornecedor. $\mathrm{Ou}$ seja, sabe-se que se essas variáveis tivessem real existência no relacionamento, o mesmo poderia alavancar benefícios para ambas as partes.

Entretanto, ao mesmo tempo em que existe essa consciência, existe também a idéia de que o custo para que fatores como a confiança e o comprometimento se estabeleçam, seja alto. A concessão de alguns benefícios ao parceiro, como torná-lo um parceiro fixo, no caso dos varejistas, exigiria a perda de outros benefícios, e no momento, fazer concessões não está nos planos desses comerciantes.

É necessário ressaltar que um relacionamento com o fornecedor baseado em comprometimento, na visão do varejista, se restringe a fatores básicos, como entrega da carga em dia, com qualidade e sem defeitos. Não existe em sua visão, a percepção de que para isso ocorrer, seja necessário haver uma ponderação entre as partes, e o comprometimento precisa ser mútuo, onde o varejista deveria se comprometer a também comprar apenas com um fornecedor, por exemplo. 
Cada comerciante varejista age individualmente nos mercados, onde questionar ações de um determinado fornecedor, quanto a suporte ou preço fixado em uma compra é uma ação tratada como antiética ou sigilosa entre os varejistas de uma cidade ou região. Foi possível observar que, entre os varejistas analisados, não existe o hábito ou interesse de união das forças, como ocorre em centrais e grupos de compras, por exemplo.

Não é possível generalizar, se tal comportamento também se observa em outras localidades, ou grupos de comerciantes, porém, nos casos analisados ficou clara a falta de conhecimento ou mesmo de interesse em tal estratégia de união. Assim, a ação individual de cada varejista fortalece a ação do atacadista, que possui um poder de barganha maior, ocupando o lado mais forte da relação.

\section{REFERÊNCIAS}

ABAD. Ranking ABAD 2010. Associação Brasileira de Atacadista e Distribuidores, 2010. ABRAS. Ranking ABRAS 2010. Revista SuperHiper, junho 2010

ALCÂNTARA, R. L. C. A gestão estratégica dos canais de distribuição um exame de evolução e do atual estagio do relacionamento entre o atacado de entrega e a industria. São Paulo, 1997. Tese (doutorado) Fundação Getúlio Vargas. São Paulo

ARNOLD J. R. T. Administração de Materiais. São Paulo: Altas, 1999, 528 p.

BEAMON, B.M. Measuring supply chain performance. International Journal of Operations \& Production Management, v.19, n. 3, p.275-292, 1999.

BERMAN, B.. Marketing channels. John Willey \& Sons, 1996, 663 p.

BLACKWELL, R. D. Da criação ao mercado: reinventando a cadeia de suprimento do varejo. São Paulo: Campus, 2001, 264 p.

BOWERSOX, D. J.; CLOSS, D. J. Logística empresarial: o processo de integração da cadeia de suprimento. São Paulo: Atlas, 2001, 602 p.

BOWERSOX, D. J.; COOPER, M.B. Strategic marketing channel management. N.Y.: McGraw-Hill Inc, 1992.

CHEN, I. J.; PAULRAJ, A.; LADO, A. A. Strategic purchasing, supply management, and firm performance. Journal of Operations Management, n.22, p.505-253, 2004.

COOPER, M.C.; LAMBERT, D.M.; PAGH, J.D. Supply chain management: more than a new name for logistics. The International Journal of Logistics Management. v.8, n.1, p.113, 1997.

COUGHLAN, A. T; ANDERSON, E.; STERN, L.W.; EL-ANSARY, A. I. Canais de Marketing e Distribuição. Porto Alegre: Bookman, 2002, $461 \mathrm{p}$

EISENHARDT, K. M. Building theories from case study research. Academy of Management Review, v.14, n.4, p.532-550, 1989.

GIOVINAZZO, R.A. Focus Group em pesquisa qualitativa: fundamentos e reflexão. Administração on Line. v.2, n. 4, outubro-dezembro 2001.

GUNASEKARAN, A; PATEL C.; TIRTIROGLU, E. Performance measures and metrics in a supply chain environment. International Journal of Operations \& Production

Management. MCB University Press, v. 21, n.1/2, p. 71-87, 2001. 
HAKANSSON, H.; SNEHOTA, I.. Developing relationships in business networks, Routledge, London, 1995, 433 p.

MARCONI, M. de A.; LAKATOS, E. M. Metodologia Científica, 4ª ed. São Paulo, Ed. Atlas, 2004.

NEVES, M. F. Um modelo para planejamento de canais de distribuição no setor de alimentos. 1999, 187 f. Tese (Doutorado em Administração). Faculdade de Economia e Administração/Universidade de São Paulo. São Paulo.

PARENTE, J. Varejo no Brasil: gestão e estratégia. São Paulo: Atlas, 2000, 388p.

PELTON, L.E.; STRUTTON, D.; LUMPKIN, J.R. Marketing channels: a relationship management approach. Times Mirror Books, 1997, 728 p.

PIGATTO, G. Avaliação de relacionamentos no canal de distribuição de produtos de mercearia básica. São Carlos, 2005. 239 p. Tese (Doutorado em Engenharia de Produção) Universidade Federal de São Carlos - UFSCar.

PNUD - Programa das Nações Unidas para o Desenvolvimento. Disponível em: $<$ http://www.pnud.org.br/home/>. Acessado em 2010.

ROSENBLOOM, B. Canais de Marketing: uma visão gerencial. São Paulo:Atlas, 2002.

SILVA, A. L. A adoção de tecnologia de informação em canais de distribuição. 1999, 144 f. Tese (Doutorado em Administração). Faculdade de Economia e Administração/Universidade de São Paulo. São Paulo.

SPEKMAN, R.E.; SPEAR, J.; KAMAUFF, J. W. Supply Chain competency: learning as a key component. Supply Chain Management: an International Journal, v.7, n.1, p.41-55, 2002 .

STERN, L. W.; EL-ANSARY, A. I; COUGHLAN, Anne T. Marketing channels. Prentice Hall, $5^{\text {a }}$ edition, 1996, 576p.

YIN, R.K. Estudo de caso: planejamento e métodos. Porto Alegre: Bookman, 2001. 